\title{
Association between body mass index (BMI) and hypertension in south Asian population: evidence from nationally- representative surveys
}

Fariha Binte Hossain ${ }^{1 \dagger}$, Gourab Adhikary ${ }^{1}$, Ariful Bari Chowdhury² and Md Shajedur Rahman Shawon ${ }^{3^{*}}$ (D)

\begin{abstract}
Background: Although there has been a well-established association between overweight-obesity and hypertension, whether such associations are heterogeneous for South Asian populations, or for different socioeconomic groups is not well-known. We explored the associations of overweight and obesity using South Asian cut-offs with hypertension, and also examined the relationships between body mass index (BMI) and hypertension in various socioeconomic subgroups.
\end{abstract}

Methods: We analysed the recent Demographic and Health Survey (DHS) data from Bangladesh, India, and Nepal, with a total of 821,040 men and women. Hypertension was defined by 2017 ACC/AHA cut-offs and by Joint National Committee 7 (JNC7) cut-offs for measured blood pressure and overweight and obesity were defined by measured height and weight. We used multiple logistic regressions to estimate the odds ratios (ORs) with 95\% confidence intervals (Cls) of hypertension for overweight and obesity as well as for each 5-unit increase in BMI.

Results: The prevalence of hypertension using JNC7 cut-offs among participants increased by age in all three countries. The prevalence ranged from $17.4 \%$ in $35-44$ years to $34.9 \%$ in $\geq 55$ years in Bangladesh, from $4.6 \%$ in $18-$ 24 years to $28.6 \%$ in $45-54$ years in India, and from $3.8 \%$ in $18-24$ years to $39.2 \%$ in $\geq 55$ years in Nepal. Men were more likely to be hypertensive than women in India and Nepal, but not in Bangladesh. Overweight and obesity using both WHO and South Asian cut-offs were associated with higher odds of hypertension in all countries. For each $5 \mathrm{~kg} / \mathrm{m}^{2}$ increase in BMl, the ORs for hypertension were 1.79 (95\% Cl: 1.65-1.93), 1.59 (95\% Cl: 1.58-1.61), and 2.03 (95\% Cl: 1.90-2.16) in Bangladesh, India, and Nepal, respectively. The associations between BMI and hypertension were consistent across various subgroups defined by sex, age, urbanicity, educational attainment and household's wealth index.

Conclusions: Our study shows that the association of BMI with hypertension is stronger for South Asian populations at even lower cut-offs points for overweight and obesity. Therefore, public health measures to reduce population-level reduction in BMI in all population groups would also help in lowering the burden of hypertension.

Keywords: Hypertension, South Asia, BMI, Overweight-obesity, Adiposity, Blood pressure

\footnotetext{
*Correspondence: md.shawon@ndph.ox.ac.uk; dr.shajedur@gmail.com

${ }^{\dagger}$ Fariha Binte Hossain and Md Shajedur Rahman Shawon contributed equally

to this work.

${ }^{3}$ Cancer Epidemiology Unit, Nuffield Department of Population Health,

University of Oxford, Richard Doll Building, Oxford OX3 7LF, UK

Full list of author information is available at the end of the article
}

(c) The Author(s). 2019 Open Access This article is distributed under the terms of the Creative Commons Attribution 4.0 International License (http://creativecommons.org/licenses/by/4.0/), which permits unrestricted use, distribution, and reproduction in any medium, provided you give appropriate credit to the original author(s) and the source, provide a link to the Creative Commons license, and indicate if changes were made. The Creative Commons Public Domain Dedication waiver (http://creativecommons.org/publicdomain/zero/1.0/) applies to the data made available in this article, unless otherwise stated. 


\section{Introduction}

Hypertension is one of the important preventable noncommunicable disease (NCD) risk factors for premature death and disability [1-3]. About one-third of world's adult population are hypertensive - according to recent reports $[4,5]$. The burden of hypertension is increasing particularly in the low- and middle-income countries (LMICs) [5]. South Asia comprises of several LMICs and almost one-quarter of the world's population lives in South Asia. Therefore, a greater understanding of the burden of hypertension in this region is required to develop public health interventions to control it.

There has been a well-established association between adiposity and hypertension in developed settings [6-8], but whether such association is heterogeneous for South Asian population is not well-known. Several previous studies have suggested that South Asian adults have substantially lower cut-off points for overweight and obesity than White Europeans, which are associated with higher risks of type 2 diabetes and cardiovascular disease [9, 10]. However, the associations between overweight and obesity at South Asian cut-offs with hypertension have not been explored adequately in the current literature lacks statistical power, national representation, or adjustments for covariates.

Assessing association between body mass index (BMI) and hypertension has important public health implications in South Asian countries, where the burden of hypertension is high and obesity is increasing at the population level [11-13]. In addition, looking at the association in subgroups defined by sex, age, urbanicity, and socioeconomic status is crucial to understand how consistent the association between BMI and hypertension is across different groups. There is no study, to the best of our knowledge, which looked at the association of BMI with hypertension across different groups in nationallyrepresentative samples from South Asian countries.

In this study, we aim to examine the age-specific prevalence of hypertension in three South Asian countries, namely Bangladesh, India, and Nepal. We also systematically assess the association between overweightobesity and hypertension using different cut-offs, and how the association between BMI and hypertension varies across a wide variety of subgroups of population.

\section{Methods}

\section{Study design and data sources}

This study is based on three South Asian countries, namely Bangladesh, India, and Nepal. Recent Demographic and Health Survey (DHS) data for these countries had information on both blood pressure and anthropometry for adult population.

DHS are periodical nationally-representative household surveys which provide data for a wide range of variables on population, health, and nutrition. These surveys usually are conducted by a national implementing agency with technical assistances provided by the DHS program. Surveys are based on two-stage stratified sampling of households - firstly, sampling census enumeration areas are selected using probability proportional to size (PPS) sampling technique through statistics provided by the respective national statistical office, and secondly, households are selected through systematic random sampling from the complete listing of households within a selected enumeration area. From these selected households, subsamples of eligible participants are additionally selected for biomarker testing, which includes height, weight, and blood pressure [14].

DHS surveys receive ethical approval both from the ICF Institutional Review Board and from a countryspecific review board. Informed consent is taken from each participant for their participation in the survey and for anthropometric and blood pressure measurements. The DHS program authorises researchers to use relevant datasets for analysis upon submission of a brief research proposal. The data we received for this study were anonymized for protection of privacy, anonymity and confidentiality. More details on survey design, ethical approval, data availability can be found in the DHS program website [https://dhsprogram.com/].

We included those who had consented for measurement of blood pressure, height, and weight, as well as had valid information for those variables. DHS surveys have very high response rate, usually more than $90 \%$. We used the household member record dataset which has one record for every household member, and includes variables for sociodemographic, height, weight and blood pressure measurement.

\section{Anthropometric measurement and BMI classification}

In the included DHS surveys, height and weight of the participants were measured by trained personnel using standardized instruments and procedures. BMI was then calculated by dividing body weight $(\mathrm{kg})$ by squared height $\left(\mathrm{m}^{2}\right)$. We classified participants based into four groups according to the conventional World Health Organization (WHO) classification system [15]: underweight $\left(<18.5 \mathrm{~kg} / \mathrm{m}^{2}\right)$, normal weight $\left(18.5-24.9 \mathrm{~kg} / \mathrm{m}^{2}\right)$, overweight $\left(25.0-29.9 \mathrm{~kg} / \mathrm{m}^{2}\right)$, and obese $\left(\geq 30.0 \mathrm{~kg} / \mathrm{m}^{2}\right)$. We also classified them according to the proposed cutoffs for South Asian population: underweight (<18.0 kg/ $\left.\mathrm{m}^{2}\right)$, normal weight $\left(18.0-22.9 \mathrm{~kg} / \mathrm{m}^{2}\right)$, overweight $\left(23.0-27.4 \mathrm{~kg} / \mathrm{m}^{2}\right)$ and obese $\left(\geq 27.5 \mathrm{~kg} / \mathrm{m}^{2}\right)$ [16].

\section{Blood pressure measurement and hypertension}

Blood pressure was measured for participants using a standard protocol [17]. In brief, three measurements were taken by trained health technicians, at seating 
position, at about $10 \mathrm{~min}$ intervals. The mean of the second and third measurement was used to record systolic blood pressure and diastolic blood pressure.

We defined hypertension based on the cut-offs provided by the Seventh Report of Joint National Committee on Prevention, Detection, Evaluation, and Treatment of High Blood Pressure (JNC7) guideline 2003 [18] and also the 2017 American College of Cardiology/American Heart Association (2017 ACC/AHA) Guideline for the Prevention, Detection, Evaluation, and Management of High Blood Pressure in Adults [19]. According to the $\mathrm{JNC7}$, an individual was categorised as hypertensive if they had systolic blood pressure $\geq 140 \mathrm{mmHg}$ or diastolic blood pressure $\geq 90 \mathrm{mmHg}$ or reported about antihypertensive medication use during the survey. According to the 2017 ACC/AHA, an individual was categorised as hypertensive if they had systolic blood pressure $\geq 130$ $\mathrm{mmHg}$ or diastolic blood pressure $\geq 80 \mathrm{mmHg}$ or reported about antihypertensive medication use during the survey.

\section{Other covariates}

DHS collected information on wide range variables from the selected households and the respondents from those households using face-to-face interview conducted by trained personnel. DHS collected information on socioeconomic factors like area of residence and household's wealth index. Place of residence (rural and urban) was defined according to country-specific definitions. For household's wealth index, each national implementing agency constructed a country-specific index using principal components analysis from data on household assets including durable goods (i.e. bicycles, televisions etc.) and dwelling characteristics (i.e. sanitation, source of drinking water and construction material of house etc.) [14]. This wealth index was then categorized into five groups (i.e. poorest, poorer, middle, richer, and richest) based on the quintile distribution of the sample.

\section{Statistical analyses}

All analyses were conducted following the instructions in the DHS guide to analysis [20]. All analyses were performed using Stata v15.1 (Statacorp, College Station, TX, USA). Considering the two-stage stratified cluster sampling in DHS, we applied Stata's survey estimation procedures ("svy" command) [21].

We looked at the descriptive statistics by sex on sociodemographic, anthropometric, and blood pressure variables using proportions for categorical variables and mean and standard deviation (SD) for continuous variables. We used sampling weights given in each DHS dataset in order to get nationally-representative estimates. 95\% confidence intervals (CIs) for prevalence estimates were calculated using a logit transform of the estimate.

To examine the association between BMI and hypertension, we used multiple logistic regressions, separately for each included country. We also estimated the trend by estimating the odds ratios (ORs) with $95 \%$ confidence intervals (CIs) of hypertension for each $5 \mathrm{~kg} / \mathrm{m}^{2}$ increase in BMI. All these analyses were adjusted for age, sex, are of residence, household's highest education level, and household's wealth index, as appropriate. We then examined the trend in subgroups of individuals defined by various characteristics.

\section{Results}

A total of 821,040 men and women from Bangladesh, India, and Nepal were included in this study. Table 1 shows that sociodemographic characteristics for three study population, by sex. Study populations varied widely for age - mean age for participants from Bangladesh was 51 years whereas the mean ages for participants from other two countries were much lower (India: 30 years and Nepal: 38 years). Almost two-thirds of the participants were from rural areas in Bangladesh and India, but Nepal had more participants from urban areas. Male participants were more likely to be educated than female participants in all countries, and India had higher proportions of men and women educated to secondary or higher level. Wealth index distributions were similar between men and women, and also among countries (Table 1).

Table 2 shows the distribution of anthropometric and blood pressure measurements for the study populations. On average, females had slightly higher BMI than males. According to both the WHO classification and South Asian classification systems, more women were overweight and obese in all three countries. In Bangladesh, women had higher systolic (mean 121.0 vs $116.2 \mathrm{mmHg}$ ) and diastolic (mean 79.6 vs $76.4 \mathrm{mmHg}$ ) blood pressure than men. In contrary, men had higher mean blood pressure than women in India (systolic: 121.8 vs 115.2 mmHg; diastolic: 79.9 vs $78.1 \mathrm{mmHg}$ ) and Nepal (systolic: 120.0 vs. $112.4 \mathrm{mmHg}$; diastolic 79.0 vs. 76.4 $\mathrm{mmHg}$ ) (Table 2). Figure. 1 shows the distribution of systolic and diastolic blood pressure in these three countries.

Overall, Bangladesh had higher prevalence of hypertension (both overall and by sex) than India and Nepal, but it is important to remember that Bangladesh had older study participants than the other two. When we looked at the age-specific prevalence of hypertension, there was a sharp increase in prevalence of hypertension by age (Fig. 2). The overall prevalence for hypertension among participants aged 35-44 years were 17.4, 20, and $22.5 \%$ for Bangladesh, India, and Nepal, respectively. For 
Table 1 Sociodemographic characteristics of three study populations, by sex

\begin{tabular}{|c|c|c|c|c|c|c|}
\hline & \multicolumn{2}{|l|}{ Bangladesh } & \multicolumn{2}{|l|}{ India } & \multicolumn{2}{|l|}{ Nepal } \\
\hline & Male & Female & Male & Female & Male & Female \\
\hline Number of participants & 3798 & 3837 & 109,527 & 689,131 & 6114 & 8633 \\
\hline Age in years, mean (SD) & $51.7(12.9)$ & $50.4(12.5)$ & $31.7(11.1)$ & $29.8(9.8)$ & $40.1(18.2)$ & $36.9(16.9)$ \\
\hline \multicolumn{7}{|c|}{ Type of place of residence, $\mathrm{n}(\%)$} \\
\hline Urban & $1253(33.0)$ & $1254(32.7)$ & $34,137(31.2)$ & 199,227 (28.9) & $3884(63.5)$ & $5459(63.2)$ \\
\hline Rural & $2545(67.0)$ & $2583(67.3)$ & $75,390(68.8)$ & $489,904(71.1)$ & $2230(36.5)$ & $3174(36.8)$ \\
\hline \multicolumn{7}{|c|}{ Highest educational level attained, n (\%) } \\
\hline No education, preschool & $1330(35.0)$ & $2112(55.0)$ & $13,874(12.7)$ & $186,695(27.1)$ & $1428(23.4)$ & $4089(47.4)$ \\
\hline Primary & $1076(28.3)$ & $1035(27.0)$ & $14,250(13.0)$ & $93,170(13.5)$ & $1278(20.9)$ & $1141(13.2)$ \\
\hline Secondary & $890(23.4)$ & $538(14.0)$ & $64,081(58.5)$ & $330,514(48.0)$ & $2398(39.2)$ & $2440(28.3)$ \\
\hline Higher & $502(13.2)$ & $152(4.0)$ & $17,064(15.6)$ & $77,464(11.2)$ & $1005(16.4)$ & $959(11.1)$ \\
\hline \multicolumn{7}{|l|}{ Wealth index, $\mathrm{n}(\%)$} \\
\hline Poorest & $681(17.9)$ & $664(17.3)$ & $18,302(16.7)$ & $132,389(19.2)$ & $1293(21.1)$ & $1917(22.2)$ \\
\hline Poorer & $702(18.5)$ & $686(17.9)$ & $22,874(20.9)$ & $147,995(21.5)$ & $1241(20.3)$ & $1792(20.8)$ \\
\hline Middle & $732(19.3)$ & $750(19.5)$ & $23,782(21.7)$ & $145,007(21.0)$ & 1185 (19.4) & 1754 (20.3) \\
\hline Richer & $769(20.2)$ & $816(21.3)$ & $22,620(20.7)$ & $135,960(19.7)$ & $1276(20.9)$ & $1738(20.1)$ \\
\hline Richest & $914(24.1)$ & $921(24.0)$ & $21,949(20.0)$ & $127,780(18.5)$ & $1119(18.3)$ & $1432(16.6)$ \\
\hline
\end{tabular}

age groups $45-54$ years, the prevalence increased to $25 \%$ in Bangladesh, $28.6 \%$ in India, and $30 \%$ in Nepal. For all age groups, men had higher prevalence of hypertension than women in India and Nepal, but not in Bangladesh. When we used the 2017 ACC/AHA guidelines to define hypertension, the prevalence estimates, as expected, increased significantly for all age groups in all three countries (Additional file 1: Fig. S1).

After adjustment for five sociodemographic factors including age, sex, area of residence, wealth index, and

Table 2 Distribution of anthropometric and blood pressure measurements among the three study populations, by sex

\begin{tabular}{|c|c|c|c|c|c|c|}
\hline & \multicolumn{2}{|l|}{ Bangladesh } & \multicolumn{2}{|l|}{ India } & \multicolumn{2}{|l|}{ Nepal } \\
\hline & Male & Female & Male & Female & Male & Female \\
\hline Weight in kg, mean (SD) & $54.2(10.4)$ & $48.0(10.9)$ & $58.3(11.5)$ & $50.3(10.6)$ & $57.2(10.6)$ & $50.1(9.9)$ \\
\hline Height in cm, mean (SD) & $161.7(6.5)$ & $149.5(5.9)$ & $163.4(7.4)$ & $152.0(6.1)$ & $162.7(6.5)$ & $151.0(6.0)$ \\
\hline BMl in kg/m², mean (SD) & $20.7(3.4)$ & $21.4(4.5)$ & $21.8(3.9)$ & $21.7(4.2)$ & $21.6(3.5)$ & $22.0(4.0)$ \\
\hline \multicolumn{7}{|l|}{ BMI category (WHO cut-offs), n (\%) } \\
\hline$<18.5 \mathrm{~kg} / \mathrm{m}^{2}$ & $1060(27.9)$ & $1090(28.4)$ & $21,035(19.2)$ & $151,161(21.9)$ & $1123(18.4)$ & $1596(18.5)$ \\
\hline $18.5-24.9 \mathrm{~kg} / \mathrm{m}^{2}$ & $2328(61.3)$ & $2016(52.5)$ & $69,208(63.2)$ & $411,908(59.8)$ & $4034(66.0)$ & $5316(61.6)$ \\
\hline $25.0-29.9 \mathrm{~kg} / \mathrm{m}^{2}$ & $374(9.8)$ & $578(15.1)$ & $16,342(14.9)$ & $96,929(14.1)$ & $825(13.5)$ & $1366(15.8)$ \\
\hline$\geq 30.0 \mathrm{~kg} / \mathrm{m}^{2}$ & $36(0.9)$ & $153(4.0)$ & $2942(2.7)$ & $29,133(4.2)$ & $132(2.2)$ & $355(4.1)$ \\
\hline \multicolumn{7}{|l|}{ BMI category (South Asian cut-offs), n (\%) } \\
\hline$<18.0 \mathrm{~kg} / \mathrm{m}^{2}$ & $835(22.0)$ & $892(23.2)$ & $15,892(14.5)$ & $117,165(17.0)$ & $808(13.2)$ & $1198(13.9)$ \\
\hline $18.0-22.9 \mathrm{~kg} / \mathrm{m}^{2}$ & $2106(55.5)$ & $1721(44.9)$ & $57,271(52.3)$ & $357,864(51.9)$ & $3523(57.6)$ & $4531(52.5)$ \\
\hline $23.0-27.4 \mathrm{~kg} / \mathrm{m}^{2}$ & $714(18.8)$ & $885(23.1)$ & $28,583(26.1)$ & $151,733(22.0)$ & $1403(22.9)$ & $2040(23.6)$ \\
\hline$\geq 27.5 \mathrm{~kg} / \mathrm{m}^{2}$ & $143(3.8)$ & $339(8.8)$ & $7781(7.1)$ & $62,369(9.1)$ & $380(6.2)$ & $864(10.0)$ \\
\hline Systolic blood pressure in mmHg, mean (SD) & $116.2(19.2)$ & $121.0(22.4)$ & $121.8(13.6)$ & $115.2(15.1)$ & $120.0(18.6)$ & $112.4(18.6)$ \\
\hline Diastolic blood pressure in mmHg, mean (SD) & $76.4(11.6)$ & $79.6(11.9)$ & $79.9(10.5)$ & $78.1(18.1)$ & $79.0(11.9)$ & $76.4(11.1)$ \\
\hline \multicolumn{7}{|l|}{ Taking prescribed medicine to lower blood pressure } \\
\hline No & $3503(92.3)$ & 3256 (84.9) & $106,839(97.5)$ & $667,872(96.9)$ & $5886(96.3)$ & 8328 (96.5) \\
\hline Yes & $293(7.7)$ & 577 (15.1) & $2686(2.5)$ & 21,239 (3.1) & $228(3.7)$ & 305 (3.5) \\
\hline
\end{tabular}




\section{(A) Systolic blood pressure}

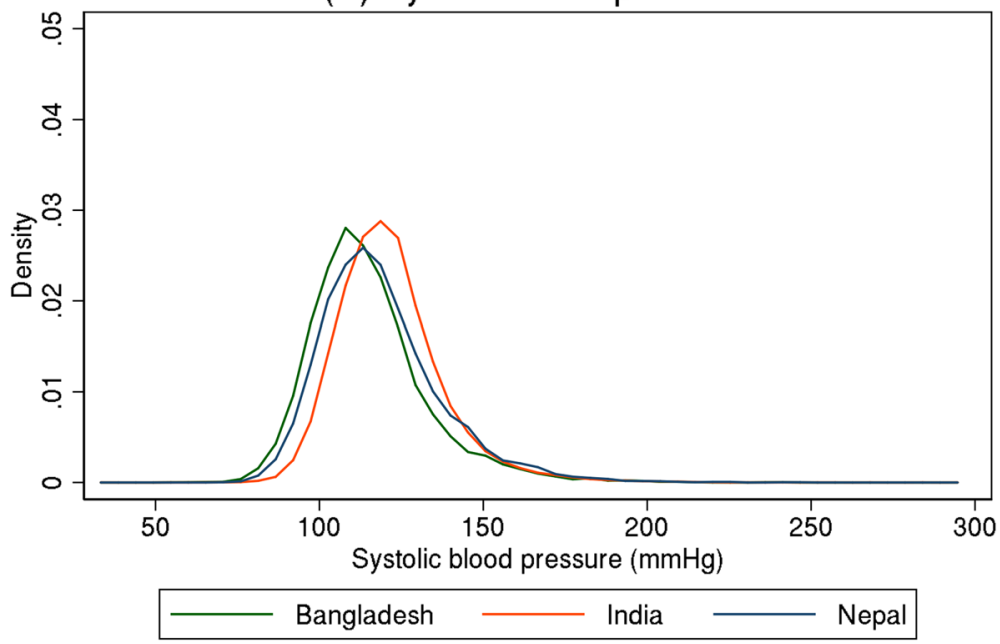

(B) Diastolic blood pressure

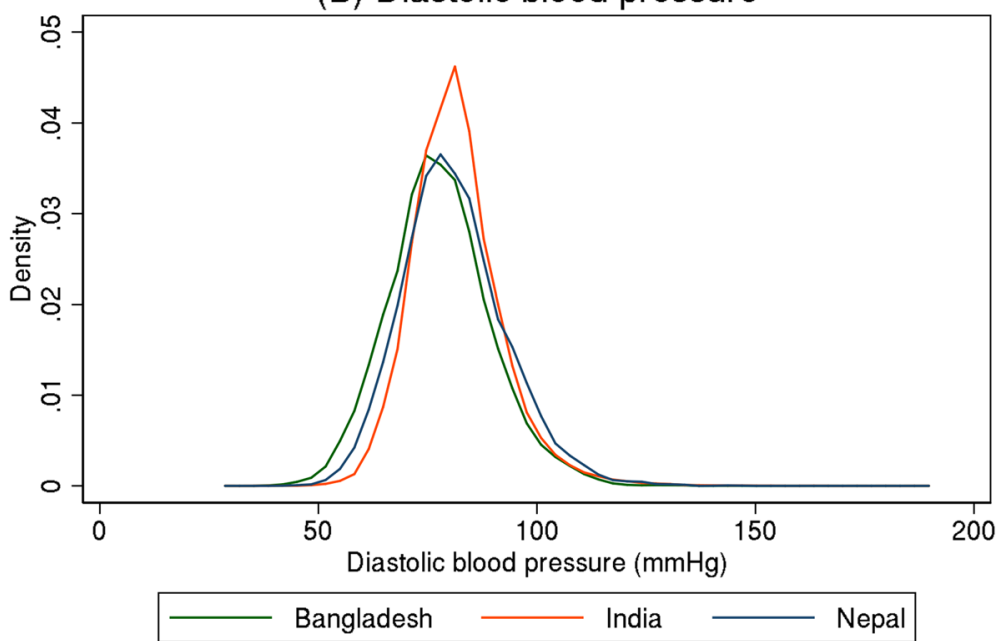

Fig. 1 Distributions of systolic and diastolic blood pressure in Bangladesh, India, and Nepal

highest educational attainment, being overweight and obese individuals, independent of classification system, had higher odds of having hypertension when compared to normal weight individuals (Table 3). Overweight people had almost two-fold increase in the odds of hypertension, whereas obese people had more than three-fold higher odds of hypertension. For each $5 \mathrm{~kg} / \mathrm{m}^{2}$ increase in BMI, the ORs for hypertension were 1.79 (95\% CI: 1.65-1.93), 1.59 (95\% CI: 1.58-1.61), and 2.03 (95\% CI: 1.90-2.16) in Bangladesh, India, and Nepal, respectively. We found similar associations between BMI and hypertension for all three countries when we used the AHA 2017 guidelines for defining hypertension (Additional file 1: Table S1).

To assess any further potential for effect modification by other factors, the OR per $5 \mathrm{~kg} / \mathrm{m}^{2}$ was compared across subgroups of various individual characteristics, including sex, area of residence, age group, highest educational attainment, and household's wealth index (Fig. 3). Weak evidence of heterogeneity in the association between BMI and hypertension was found by sex (higher magnitude in males than females) in India and Nepal. For other characteristics, no significant heterogeneity was observed by subgroups consistently in three study populations.

\section{Discussion}

This study involving more than 800,000 men and women from recent nationally-representative crosssectional studies in three South Asian countries showed high prevalence of hypertension, particularly with increasing age. There were significant associations between overweight-obesity and hypertension, irrespective of cutoffs for defining overweight-obesity as well as 


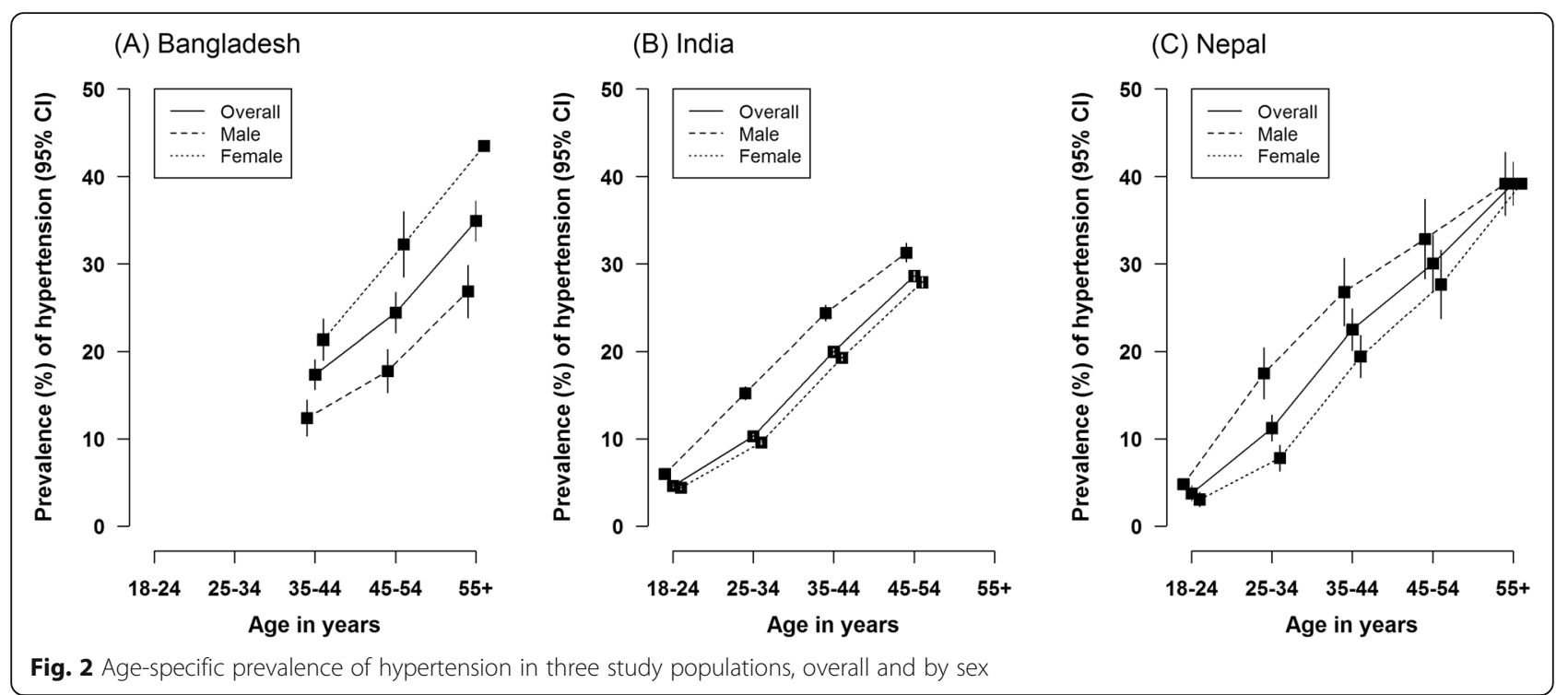

hypertension. The associations between BMI and hypertension were consistent across various subgroups defined by sex, age, urbanicity, educational attainment and household's wealth index, implying the robustness of such association.

Our study showed that almost one in every five adults aged 35 years and above in Bangladesh, India, and Nepal had hypertension. A recent systematic review [13] showed considerable differences in prevalence estimates of hypertension in South Asian countries, but it did not consider the effects of differential age structure in the included studies. When we looked at the age-specific prevalence of hypertension, the country-specific prevalence estimates were almost similar. We found higher prevalence of hypertension among men than among women in India and Nepal, but not in Bangladesh.
However, previous studies from this region mostly found the prevalence of hypertension was higher among men than among women [22-26]. Systematic analysis of population-based studies from 90 countries showed that the age-standardized prevalence of hypertension between 2000 and 2010 decreased by $2.6 \%$ in developed countries, while in LMICs it increased by $7.7 \%$ during the same period [5]. The high prevalence of hypertension in these three counties could be due to adoption of unhealthy lifestyles including intake of energy-dense foods, sedentary lifestyles, and rising level of obesity in the population $[5,12,22,26]$.

Positive associations between BMI and hypertension have been well reported in studies conducted among different ethnic groups [6-8, 27-30]. However, previous studies found that Asian populations had a much

Table 3 Adjusted odds ratios (ORs) with 95\% Cl for hypertension by BMl

\begin{tabular}{|c|c|c|c|c|c|c|}
\hline & \multicolumn{2}{|l|}{ Bangladesh } & \multicolumn{2}{|l|}{ India } & \multicolumn{2}{|l|}{ Nepal } \\
\hline & No. of cases & OR $(95 \% \mathrm{Cl})^{+}$ & No. of cases & $\mathrm{OR}(95 \% \mathrm{Cl})^{\dagger}$ & No. of cases & $\mathrm{OR}(95 \% \mathrm{Cl})^{\dagger}$ \\
\hline \multicolumn{7}{|l|}{ BMI categories (WHO cut-offs) } \\
\hline Underweight $\left(<18.5 \mathrm{~kg} / \mathrm{m}^{2}\right)$ & 383 & $0.57(0.50-0.65)$ & 12,121 & $0.70(0.69-0.72)$ & 301 & $0.55(0.48-0.63)$ \\
\hline Normal weight $\left(18.5-25.0 \mathrm{~kg} / \mathrm{m}^{2}\right)$ & 1110 & $1.00(0.93-1.07)$ & 55,386 & $1.00(0.99-1.01)$ & 1519 & $1.00(0.94-1.06)$ \\
\hline Overweight $\left(25.0-29.9 \mathrm{~kg} / \mathrm{m}^{2}\right)$ & 394 & $1.80(1.57-2.07)$ & 27,738 & $1.99(1.96-2.02)$ & 757 & $2.46(2.24-2.71)$ \\
\hline Obese $\left(\geq 30.0 \mathrm{~kg} / \mathrm{m}^{2}\right)$ & 108 & $2.72(2.00-3.68)$ & 10,762 & $3.03(2.96-3.11)$ & 213 & $3.62(2.97-4.41)$ \\
\hline \multicolumn{7}{|l|}{ BMI categories (South Asian cut-offs) } \\
\hline Underweight $\left(<18.0 \mathrm{~kg} / \mathrm{m}^{2}\right)$ & 322 & $0.73(0.63-0.83)$ & 9221 & $0.79(0.77-0.80)$ & 233 & $0.65(0.56-0.76)$ \\
\hline Normal weight $\left(18.0-23.0 \mathrm{~kg} / \mathrm{m}^{2}\right)$ & 820 & $1.00(0.92-1.09)$ & 40,596 & $1.00(0.99-1.01)$ & 1145 & $1.00(0.93-1.07)$ \\
\hline Overweight (23.0-27.0 kg/m²) & 614 & $2.14(1.93-2.38)$ & 34,799 & $1.76(1.74-1.79)$ & 911 & $2.03(1.87-2.20)$ \\
\hline Obese $\left(\geq 27.0 \mathrm{~kg} / \mathrm{m}^{2}\right)$ & 239 & $2.99(2.46-3.64)$ & 21,391 & $3.04(2.99-3.10)$ & 501 & $3.64(3.19-4.16)$ \\
\hline Trend (per $5 \mathrm{~kg} / \mathrm{m}^{2}$ ) & 1995 & $1.79(1.65-1.93)$ & 106,007 & $1.59(1.58-1.61)$ & 2790 & $2.03(1.90-2.16)$ \\
\hline
\end{tabular}

\footnotetext{
${ }^{\dagger}$ Logistic regression models were adjusted for age, sex, area of residence, wealth index and highest educational attainment
} 


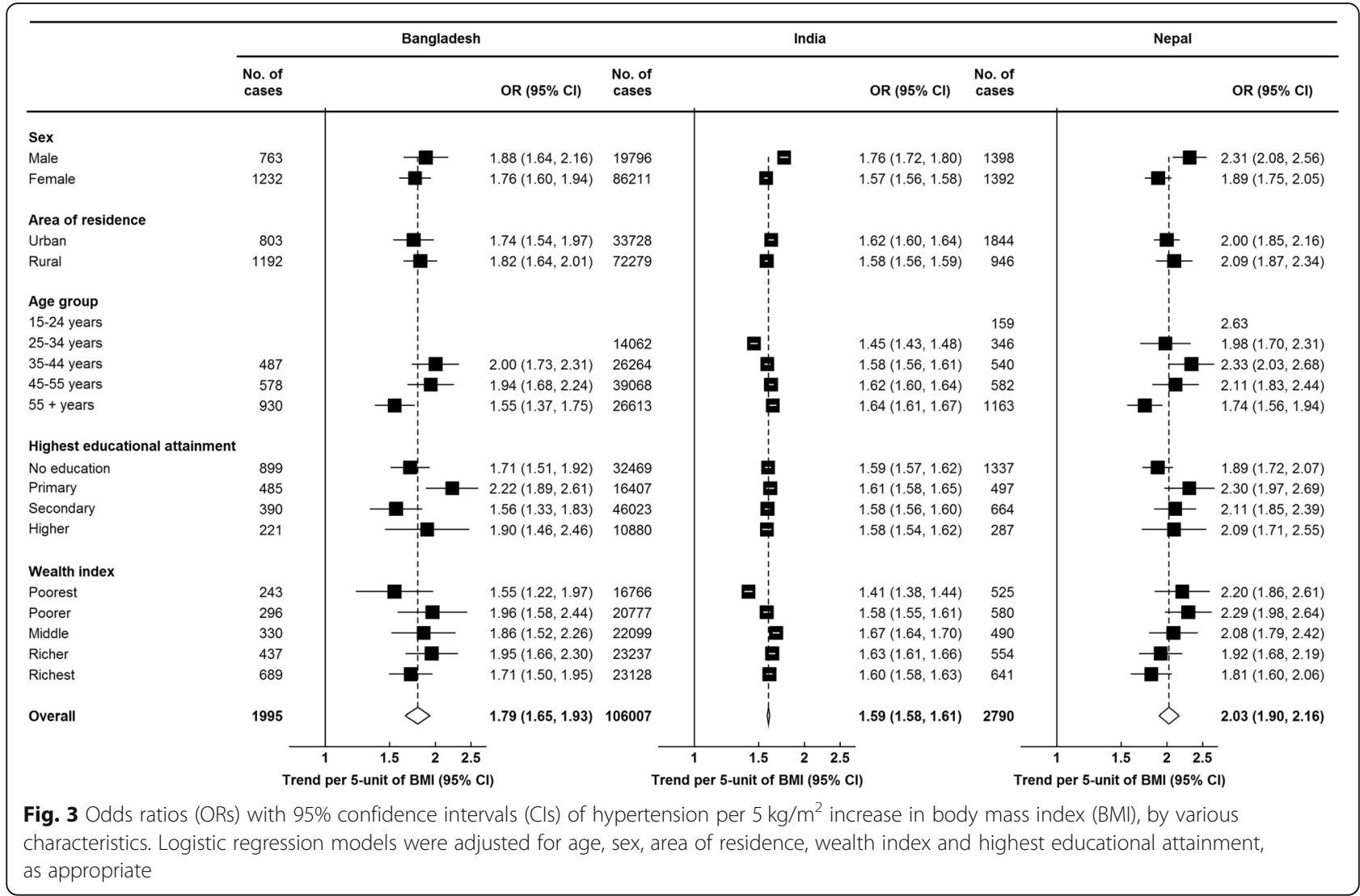

stronger association between BMI and blood pressure $[28,29]$. Our study adds to the evidence suggesting that there are ethnic differences in the strength of the association between BMI and hypertension. South Asian populations may be at greater risk of developing hypertension with increasing BMI than any other ethnic groups [30]. BMI has been found to be associated with hypertension, diabetes, and other NCDs in South Asian populations, at a much lower threshold level than the level for other populations [22, 23, 31]. The possible reasons for such differences could be genetic and metabolic variations, as well as clustering of environmental, dietary, and social factors associated with hypertension [11, 29-31].

Previous studies looking at the relationship between adiposity and hypertension in this population were heterogeneous in terms of definitions used for overweight and obesity [13, 23-25]. We looked at the association using both WHO and South Asian cut-offs and also for each 5 $\mathrm{kg} / \mathrm{m}^{2}$ increase in BMI. Our findings on the association between BMI and hypertension are consistent with previous literature [6-8]. Additionally, we were able to show that this association is consistent across a wide range of subgroups defined by various characteristics. This means that the association between BMI and hypertension is more likely to be biological rather than environmental.
Since BMI is log-linearly associated with hypertension, any amount of reduction in BMI at population level can reduce the burden of hypertension at a large scale. Early diagnosis and treatment of hypertension is crucial for reducing NDC burden in South Asian countries [25], but given the robust and linear association between BMI and hypertension, primary prevention through reducing BMI would have much greater effect on reduction of cardiovascular morbidity and mortality. The current life expectancy in Bangladesh, India and Nepal are 72.4, 68.7 , and 70.6 years, respectively, whereas cardiovascular diseases and cancers are the leading cause of death in these countries. Previous studies found that awareness about high blood pressure and use of antihypertensive medication is low in this region [24, 25, 32]. Also, the health systems are not well-prepared to manage the large burden of NDCs [33, 34]. Therefore, the policy makers should focus mainly on reduction of BMI at population level as one of the most important primary prevention strategies.

This study was limited by the use of cross-sectional data. There are possibilities of reverse causation; and we cannot establish a causal association between BMI and hypertension, or whether BMI is an independent risk factor of hypertension. We did not have dietary and lifestyle variables which could be potential mediators or 
could confound the observed associations. However, to the best of our knowledge, our study is the first to look at the association between BMI and hypertension in various subgroups of population. Taking advantage of the large sample size of our study, we were able to show that the associations of BMI with hypertension were robust across various socioeconomic subgroups. We also did several additional analyses using different cut-offs for defining both overweight-obesity and hypertension.

\section{Conclusions}

In conclusion, the age-specific prevalence of hypertension is very high among men and women in Bangladesh, India, and Nepal. The associations of BMI with hypertension are positive and robust across various subgroups of population defined by socioeconomic groups. Public health interventions targeting to reduce BMI at population level would have larger effects on reducing the burden of hypertension in South Asia.

\section{Supplementary information}

Supplementary information accompanies this paper at https://doi.org/10. 1186/s40885-019-0134-8.

Additional file 1: Fig. S1. Prevalence of hypertension according to American Heart Association guideline 2017, overall and by sex. Table S1. Adjusted odds ratios (ORs) with $95 \% \mathrm{Cl}$ for hypertension defined by the American Heart Association 2017 guideline, by BMI.

\section{Acknowledgements}

The authors thank the participants of Demographic and Health Surveys used in this study from Bangladesh, India, and Nepal. We would also like to thank the DHS Program to authorize us to use the data.

\section{Conflict of interests}

None declared.

\section{Authors' contributions}

Conception and design: FH, MS, GA, and AC. Data collection and management: FH, MS, and GA. Data analysis: FH, MS, GA. Interpretation of the results: All authors. Drafting of the article: FH and MS. Critical revision of the article for important intellectual content: All authors. Final approval of the article: All authors

\section{Funding}

This work was not supported by any funding.

\section{Availability of data and materials}

This study used data from Demographic and Health Surveys (DHS) for Bangladesh, India, and Nepal, which are available from the DHS programme website (www.dhsprogram.com)

\section{Ethics approval and consent to participate}

Demographic and Health Surveys (DHS) receive ethical approval both from the ICF Institutional Review Board and from a country-specific review board. Informed consent is taken from each participant for their participation in the survey and for anthropometric and blood pressure measurements.

\section{Consent for publication}

Not applicable.

\section{Competing interests}

None declared.

\section{Author details}

${ }^{1}$ Independent Researcher, Dhaka, Bangladesh. ${ }^{2}$ Department of Public Health, North South University, Dhaka, Bangladesh. ${ }^{3}$ Cancer Epidemiology Unit, Nuffield Department of Population Health, University of Oxford, Richard Doll Building, Oxford OX3 7LF, UK.

Received: 4 August 2019 Accepted: 18 November 2019

Published online: 15 December 2019

\section{References}

1. Forouzanfar Mohammad $\mathrm{H}$, et al. "Global, regional, and national comparative risk assessment of 79 behavioural, environmental and occupational, and metabolic risks or clusters of risks, 1990-2015: a systematic analysis for the Global Burden of Disease Study 2015". Lancet. 2016:388:10053(2016):1659-724.

2. Lawes CMM, Vander Hoorn S, Rodgers A. Global burden of blood-pressurerelated disease, 2001. Lancet (London, England). 2008;371:1513-8.

3. Kearney PM, Whelton M, Reynolds K, Muntner P, Whelton PK, He J. Global burden of hypertension: analysis of worldwide data. Lancet (London, England). 2005;365:217-23.

4. Zhou B, Bentham J, Di Cesare M, Bixby H, Danaei G, Cowan MJ, et al. Worldwide trends in blood pressure from 1975 to 2015: a pooled analysis of 1479 population-based measurement studies with 19.1 million participants. Lancet. 2017;389:37-55.

5. Mills KT, Bundy JD, Kelly TN, Reed JE, Kearney PM, Reynolds K, et al. Global disparities of hypertension prevalence and control: a systematic analysis of population-based studies from 90 countries. Circulation. 2016;134:441-50.

6. Gelber RP, Gaziano JM, Manson JE, Buring JE, Sesso HD. A prospective study of body mass index and the risk of developing hypertension in men. Am J Hypertens. 2007;20:370-7.

7. Droyvold WB, Midthjell K, Nilsen TIL, Holmen J. Change in body mass index and its impact on blood pressure: a prospective population study. Int J Obes. 2005;29:650-5.

8. Shuger SL, Sui X, Church TS, Meriwether RA, Blair SN. Body mass index as a predictor of hypertension incidence among initially healthy normotensive women. Am J Hypertens. 2008;21:613-9.

9. Gray LJ, Yates T, Davies MJ, Brady E, Webb DR, Sattar N, et al. Defining obesity cut-off points for migrant south Asians. PLoS One. 2011;6.

10. Misra A. Ethnic-specific criteria for classification of body mass index: a perspective for Asian Indians and American Diabetes Association position statement. Diabetes Technol Ther. 2015;17:667-71.

11. Misra A, Jayawardena R, Anoop S. Obesity in South Asia: phenotype, morbidities, and mitigation. Curr Obes Rep. 2019:8:43-52.

12. Ramachandran A, Snehalatha C. Rising burden of obesity in Asia. J Obes. 2010;2010:868573. https://doi.org/10.1155/2010/868573.

13. Neupane D, McLachlan CS, Sharma R, Gyawali B, Khanal V, Mishra SR, et al. Prevalence of hypertension in member countries of south Asian Association for Regional Cooperation (SAARC): systematic review and meta-analysis. Medicine (Baltimore). 2014;93:e74. https://doi.org/10.1097/MD. 0000000000000074.

14. The DHS Program. DHS Overwiew 2019. https://dhsprogram.com/What-WeDo/Survey-Types/DHS.cfm. Accessed 3 Apr 2019.

15. Expert Panel on the Identification, Evaluation, and Treatment of Overweight and Obesity in Adults. Executive summary of the clinical guidelines on the identification, evaluation, and treatment of overweight and obesity in adults. Arch Intern Med. 1998;158(17):1855-67.

16. Stegenga $\mathrm{H}$, Haines $\mathrm{A}$, Jones $\mathrm{K}$, Wilding J. Identification, assessment, and management of overweight and obesity: summary of updated NICE guidance. BMJ Br Med J. 2014;349:g6608. https://doi.org/10.1136/bmj.g6608.

17. ICF International / Demographic and Health Surveys. Biomarker Field Manual: Demographic and Health Survey Methodology. Maryland, USA; 2012. https://www.dhsprogram.com/publications/publication-dhsm7-dhsquestionnaires-and-manuals.cfm.

18. Chobanian AV, Bakris GL, Black HR, Cushman WC, Green LA, Izzo JL, et al. The seventh report of the joint National Committee on prevention, detection, evaluation, and treatment of high blood pressure: the JNC 7 report. JAMA. 2003;289:2560-72.

19. Whelton PK, Carey RM, Aronow WS, Casey DEJ, Collins KJ, Dennison Himmelfarb C, et al. 2017 ACC/AHA/AAPA/ABC/ACPM/AGS/APhA/ASH/ ASPC/NMA/PCNA guideline for the prevention, detection, evaluation, and Management of High Blood Pressure in adults: executive summary: a report 
of the American College of Cardiology/American Heart Association task F. Hypertens (Dallas, Tex 1979). 2018;71:1269-324.

20. DHS Program. Using datasets for analysis. https://dhsprogram.com/data/ Using-Datasets-for-Analysis.cfm. .

21. StataCorp. svy estimation - Estimation commands for survey data. https:// www.stata.com/manuals13/svysvyestimation.pdf. Accessed 3 Apr 2019

22. Gupta R, Gaur K, CV SR. Emerging trends in hypertension epidemiology in India. J Hum Hypertens. 2018.

23. Geldsetzer P, Manne-Goehler J, Theilmann M, Davies JI, Awasthi A, Vollmer $S$, et al. Diabetes and hypertension in India: a nationally representative study of 1.3 million AdultsDiabetes and hypertension in IndiaDiabetes and hypertension in India. JAMA Intern Med. 2018;178:363-72. https://doi.org/10. 1001/jamainternmed.2017.8094.

24. Roy A, Praveen PA, Amarchand R, Ramakrishnan L, Gupta R, Kondal D, et al. Changes in hypertension prevalence, awareness, treatment and control rates over 20 years in National Capital Region of India: results from a repeat cross-sectional study. BMJ Open. 2017;7.

25. Mehata S, Shrestha N, Mehta R, Vaidya A, Rawal LB, Bhattarai N, et al. Prevalence, awareness, treatment and control of hypertension in Nepal: data from nationally representative population-based cross-sectional study. J Hypertens. 2018;36:1680-8.

26. Islam AKMM, Majumder AAS. Hypertension in Bangladesh: a review. Indian Heart J. 2012;64:319-23. doi:https://doi.org/10.1016/S0019-4832(12)60096-0.

27. Cassano PA, Segal MR, Vokonas PS, Weiss ST. Body fat distribution, blood pressure, and hypertension. A prospective cohort study of men in the normative aging study. Ann Epidemiol. 1990;1:33-48.

28. Hu FB, Wang B, Chen C, Jin Y, Yang J, Stampfer MJ, et al. Body mass index and cardiovascular risk factors in a rural Chinese population. Am J Epidemiol. 2000;151:88-97.

29. Linderman GC, Lu J, Lu Y, Sun X, Xu W, Nasir K, et al. Association of Body Mass Index With Blood Pressure Among 1.7 Million Chinese Adults. JAMA Netw open. 2018;1:e181271.

30. McKeigue PM, Shah B, Marmot MG. Relation of central obesity and insulin resistance with high diabetes prevalence and cardiovascular risk in South Asians. Lancet (London, England). 1991;337:382-6.

31. Hills AP, Arena R, Khunti K, Yajnik CS, Jayawardena R, Henry CJ, et al. Epidemiology and determinants of type 2 diabetes in south Asia. lancet Diabetes Endocrinol. 2018;6:966-78.

32. Rahman M, Williams G, Al MA. Gender differences in hypertension awareness, antihypertensive use and blood pressure control in Bangladeshi adults: findings from a national cross-sectional survey. J Health Popul Nutr. 2017;36.

33. Sengupta A, Zaidi S, Sundararaman T, Onta S, Weerasinghe MC. Tackling the primary care access challenge in South Asia. BMJ. 2018;363:k4878. https:// doi.org/10.1136/bmj.k4878.

34. Zaidi S, Saligram P, Ahmed S, Sonderp E, Sheikh K. Expanding access to healthcare in South Asia. BMJ. 2017;357:j1645. https://doi.org/10.1136/bmj. j1645.

\section{Publisher's Note}

Springer Nature remains neutral with regard to jurisdictional claims in published maps and institutional affiliations.

\section{Ready to submit your research? Choose BMC and benefit from:}

- fast, convenient online submission

- thorough peer review by experienced researchers in your field

- rapid publication on acceptance

- support for research data, including large and complex data types

- gold Open Access which fosters wider collaboration and increased citations

- maximum visibility for your research: over $100 \mathrm{M}$ website views per year

At $\mathrm{BMC}$, research is always in progress.

Learn more biomedcentral.com/submissions 